\title{
Mean Platelet Volume and Vitamin D Level
}

\author{
Medine Cumhur Cure, M.D. ${ }^{1}$, Erkan Cure, M.D. ${ }^{2}$, Suleyman Yuce, M.D. ${ }^{2}$, TarkanYazici, M.D. ${ }^{1}$, Inanc Karakoyun, M.D. ${ }^{3}$, \\ and Hasan Efe, M.D. ${ }^{1}$ \\ Departments of Biochemistry ${ }^{1}$ and Internal Medicine ${ }^{2}$, University of Recep Tayyip Erdogan, Rize; Department of Biochemistry ${ }^{3}$, Izmir Public Health \\ Laboratory, Izmir, Turkey
}

Background: Vitamin D deficiency and a high mean platelet volume (MPV) are related to cardiovascular disease. We investigated whether vitamin D deficiency is associated with high MPV.

Methods: This study included 434 patients without chronic disease who were not taking vitamin D or calcium supplements. Vitamin D was measured by chemiluminescent microparticle immunoassay on the Architect-I2000 system (Abbott Diagnostics, USA), and MPV was measured on the Cell-Dyn Ruby analyzer (Abbott Diagnostics). Patients were divided into Groups 1 (138 [men/women, 46/92]), 2 (148 [men/women, 54/94]), and 3 (148 [men/women, 50/98]) according to vitamin D levels of $<10 \mathrm{ng} / \mathrm{mL}, 10-20 \mathrm{ng} / \mathrm{mL}$, and $>20 \mathrm{ng} / \mathrm{mL}$, respectively.

Results: The vitamin D level in Group $1(7.7 \pm 1.9 \mathrm{ng} / \mathrm{mL})$ was lower than that in Group 2 $(15.1 \pm 1.6 \mathrm{ng} / \mathrm{mL}, P<0.001)$ and Group $3(25.6 \pm 6.3 \mathrm{ng} / \mathrm{mL}, P<0.001)$. The MPV in Group $3(7.5 \pm 1.0 \mathrm{fL})$ was lower than that in Group $1(8.1 \pm 1.1 \mathrm{fL}, P<0.001)$ and Group $2(7.9 \pm 1.0 \mathrm{fL}, P=0.009)$. Linear regression analysis showed that low levels of vitamin $D$ ( $\beta=-0.109, P=0.019$ ) was independently associated with increased MPV.

Conclusions: There was a strong association between a low vitamin D level and a high MPV; therefore, vitamin D deficiency may be associated with increased MPV.

Key Words: Vitamin D, Deficiency, Mean platelet volume, Cardiovascular diseases
Received: July 18, 2013

Revision received: September 12, 2013

Accepted: December 17, 2013

\section{Corresponding author:}

Medine Cumhur Cure

Department of Biochemistry, School of Medicine, University of Recep Tayyip

Erdogan, Islampasa Mahallesi, Rize 53100, Turkey

Tel: +90-464-213-0491-1874

Fax: +90-464-217-0364

E-mail: medinecure@yahoo.com

\begin{abstract}
() The Korean Society for Laboratory Medicine
This is an Open Access article distributed under the terms of the Creative Commons Attribution Non-Commercial License (http://creativecommons.org/licenses/by-nc/3.0) which permits unrestricted non-commercial use, distribution, and reproduction in any medium, provided the original work is properly cited.
\end{abstract}

\section{INTRODUCTION}

Mean platelet volume (MPV), which reflects the size of platelets, is an accepted marker of platelet function [1]. Measuring MPV is inexpensive and can be included in routine blood tests. On comparison of the two platelet types, larger platelets have more granules, aggregate more rapidly with collagen, have a higher thromboxane A2 level, and express more glycoprotein Ib and IIb/IIla receptors than smaller platelets [2]; however, both secrete substances that are important mediators of coagulation, inflammation, thrombosis, and atherosclerosis. Therefore, platelets can increase the incidence of occlusive vascular disease [3, 4]. Studies have shown that MPV levels are associated with both arterial and venous diseases, such as coronary artery disease [5], diabetes [6], stroke [7], hypertension [8], and venous thrombo- embolism [9].

The main function of vitamin $D$ is calcium metabolism and bone structure. Vitamin D deficiency is a major health problem that affects all age groups, and is associated with rickets in children and osteoporosis in adults. In adults, the deficiency may contribute to the etiology of hypertension and other adverse cardiovascular effects [10], cancer [11], and impaired cognitive function [12]. Vitamin D supplementation improves cognitive function [13] and decreases cardiovascular disease incidence [14]. Vitamin D deficiency can also lead to immunological diseases and inflammation. Vitamin D has many different functions in humans; for example, it acts as an immunomodulatory factor [15]. In addition, the levels of proinflammatory cytokines such as tumor necrosis factor alpha (TNF- $\alpha$ ) and interleukin (IL)-6 are increased in vitamin D deficiency [16]. While vitamin D sup- 
plementation restores immune function and decreases cytokines levels [17], elevated cytokine levels lead to increased MPV $[4,18]$. However, vitamin D decreases the expression of the various adhesion molecules, thus preventing platelet activation and decreasing fibrinolysis and thrombosis [19]. In patients with vitamin D deficiency, the combined effect of elevated TNF- $\alpha$ and IL-6 levels and increased release of adhesion molecules may lead to an increased MPV. Therefore, we aimed to investigate whether vitamin D deficiency is associated with high MPV.

\section{METHODS}

\section{Patients}

This study was an observational cross-sectional study carried out at the Internal Medicine Department of Faculty of Medicine of Recep Tayyip Erdogan University from March in 2012 to May in 2013. A total of 438 patients (288 women and 150 men) were included in the patient groups who visited our internal medicine clinic with simple complaints such as headache, low back pain, and simple abdominal pain, etc., without concomitant diseases. They were nonsmokers, not taking calcium or vitamin D supplements, not consuming alcohol or using drugs. The study excluded patients with a history of diabetes, hypertension, hyperlipidemia, coronary artery disease, chronic obstructive pulmonary disease, vitamin $\mathrm{D}$ deficiency, and calcium metabolic disorders, etc. All blood samples were collected in the spring season. The literature states that patients with vitamin D levels $<10 \mathrm{ng} /$ $\mathrm{mL}$ have vitamin $D$ deficiency that is associated with a very high cardiac risk and those with vitamin D levels $<20 \mathrm{ng} / \mathrm{mL}$ have vitamin D insufficiency associated with just an increased cardiac risk [20]. Thus, we divided patients into three groups as follows: Group 1, vitamin D level of $<10 \mathrm{ng} / \mathrm{mL}(\mathrm{n}=138 ; 46$ men and 92 women); Group 2, vitamin D level of 10-20 ng/mL ( $n=148 ; 54$ men and 94 women); and Group 3, vitamin D level of $>20 \mathrm{ng} /$ $\mathrm{mL}(\mathrm{n}=148 ; 50$ men and 98 women).

\section{Laboratory tests}

Biochemical parameters were measured after a 12-hr fast. Biochemical tests that measured fasting plasma glucose (FPG), AST, ALT, blood urea nitrogen (BUN), and creatinine were performed by using photometric assays on the Architect c16000 analyzer (Abbott Diagnostics, Abbott Park, IL, USA). Hematologic tests that measured $\mathrm{Hb}$, platelets, white blood cells (WBC), and MPV were performed by using the Cell-Dyn Ruby analyzer (Abbott Diagnostics). Serum levels of vitamin D (25-hydroxyvitamin D) were measured by chemiluminescent microparticle im- munoassay on the Architect-I 2000 system (Abbott Diagnostics).

\section{Ethics}

The study conformed to the principles outlined in the Declaration of Helsinki and was approved by the local ethics committee of Recep Tayyip Erdogan University, School of Medicine, Rize, Turkey.

\section{Statistical analyses}

Among patients with a vitamin D level $>20 \mathrm{ng} / \mathrm{mL}$, the mean vitamin D level was $<30 \mathrm{ng} / \mathrm{mL}$. The MPV and other laboratory test results were evaluated separately for all three groups. In addition, statistical analyses were repeated for all patients with a vitamin D level of $<20 \mathrm{ng} / \mathrm{mL}$ and $>20 \mathrm{ng} / \mathrm{mL}$ so that we could investigate the association between a vitamin D level of $<20 \mathrm{ng} /$ $\mathrm{mL}$ and a high MPV.

Results are reported as the mean \pm SD. All data were analyzed using the statistical software SPSS for Windows (version 13.1, SPSS, Chicago, IL, USA). All continuous variables were checked with Kolmogorov-Smirnov normality test to show their distributions. The continuous variables in all groups showed a normal distribution. The differences in all parameters between the three groups were analyzed using two by two tables and performing a t-test for independent samples. Subgroup analyses for gender were performed using nested ANOVA followed by the Bonferroni analysis. Linear regression analysis was performed to determine the presence of an independent relationship between the MPV and the vitamin $\mathrm{D}$ level with other potential confounding variables. The relationship between these variables was analyzed using Pearson's correlation. Differences were considered significant at $P<0.05$.

\section{RESULTS}

Patients' demographic characteristics and laboratory values are shown in Table 1. The mean age in Group 1, 2, and 3 was $47.5 \pm$

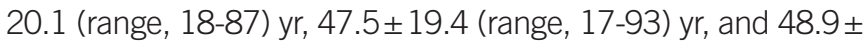
17.3 (range, 18-83) yr, respectively. Vitamin D level in Group 1 $(7.7 \pm 1.9 \mathrm{ng} / \mathrm{mL})$ was significantly lower than that in Group 2 $(15.1 \pm 1.6 \mathrm{ng} / \mathrm{mL}, P<0.001)$ and Group $3(25.6 \pm 6.3 \mathrm{ng} / \mathrm{mL}$, $P<0.001)$. The MPV in Group $3(7.5 \pm 1.0 \mathrm{fL})$ was significantly lower than that in Group $1(8.1 \pm 1.1 \mathrm{fL}, P<0.001)$ and Group 2 $(7.9 \pm 1.0 \mathrm{fL}, P=0.009)$. The Hb level, WBC count, and platelet level of Groups 1, 2, and 3 were similar (Table 1).

Patients were divided into two groups according to a vitamin D level of $<20 \mathrm{ng} / \mathrm{mL}$ or $>20 \mathrm{ng} / \mathrm{mL}$ (Table 2). The MPV in pa- 
tients with a vitamin D level of $<20 \mathrm{ng} / \mathrm{mL}$ was significantly higher than that in patients with a vitamin $D$ level of $>20 \mathrm{ng} / \mathrm{mL}$ (7.9 $\pm 1.0 \mathrm{fL}$ vs. $7.5 \pm 1.1 \mathrm{fL}, P=0.003)$.

Vitamin D level and MPV were evaluated after stratifying patients according to gender, for each group in Table 3. Vitamin D

Table 1. Patient characteristics and laboratory parameters by vitamin D level

\begin{tabular}{lccc}
\hline & Group 1 & Group 2 & Group 3 \\
& Vitamin D & Vitamin D & Vitamin D \\
N=434 & $<10 \mathrm{ng} / \mathrm{mL}$ & $10-20 \mathrm{ng} / \mathrm{dL}$ & $>20 \mathrm{ng} / \mathrm{mL}$ \\
& $\mathrm{N}=138$ & $\mathrm{~N}=148$ & $\mathrm{~N}=148$ \\
\hline Age (yr) & $47.5 \pm 20.1$ & $47.5 \pm 19.4$ & $48.9 \pm 17.3$ \\
Gender (M/F) (N) & $46 / 92$ & $54 / 94$ & $50 / 98$ \\
Vitamin D (ng/mL) & $7.7 \pm 1.9$ & $15.1 \pm 1.6^{*}$ & $25.6 \pm 6.3^{*, \dagger}$ \\
MPV (fL) & $8.1 \pm 1.1$ & $7.9 \pm 1.0$ & $7.5 \pm 1.0^{*, \neq}$ \\
Hb (g/dL) & $12.8 \pm 1.3$ & $12.7 \pm 1.6$ & $13.0 \pm 1.4$ \\
WBC ( $\left.\times 10^{9} / \mathrm{L}\right)$ & $7.1 \pm 2.1$ & $7.0 \pm 1.8$ & $7.0 \pm 2.2$ \\
Platelets $\left(\times 10^{9} / \mathrm{L}\right)$ & $269 \pm 76$ & $263 \pm 71$ & $268 \pm 67$ \\
FPG $(\mathrm{mmol} / \mathrm{L})$ & $5.5 \pm 0.6$ & $5.4 \pm 0.6$ & $5.4 \pm 0.5$ \\
BUN $(\mathrm{mmol} / \mathrm{L})$ & $10.1 \pm 3.9$ & $11.2 \pm 4.4$ & $12.1 \pm 3.9$ \\
Creatinine $(\mu \mathrm{mol} / \mathrm{L})$ & $56.4 \pm 9.9$ & $61.0 \pm 14.4$ & $61.0 \pm 12.2$ \\
AST $(\mathrm{IU} / \mathrm{L})$ & $18.6 \pm 5.7$ & $19.5 \pm 6.7$ & $20.1 \pm 70$ \\
ALT $(\mathrm{IU} / \mathrm{L})$ & $17.3 \pm 10.2$ & $19.8 \pm 13.3$ & $21.4 \pm 15.7$ \\
\hline
\end{tabular}

Results are listed as mean $\pm \mathrm{SD}$.

${ }^{*} P<0.001$ vs. vitamin $D$ level $<10 \mathrm{ng} / \mathrm{mL} ;{ }^{\dagger} P<0.001$ vs. vitamin $D$ level, $10-20 \mathrm{ng} / \mathrm{mL} ;{ }^{\ddagger} P=0.009$ vs. vitamin D level, $10-20 \mathrm{ng} / \mathrm{mL}$.

Abbreviations: MPV, mean platelet volume; WBC, white blood cells; FPG, fasting plasma glucose; BUN, blood urea nitrogen.

Table 2. Laboratory parameters according to extreme levels of vita$\min \mathrm{D}$

\begin{tabular}{lccc}
\hline & Vitamin D $<20 \mathrm{ng} / \mathrm{mL}$ & Vitamin D $\geq 20 \mathrm{ng} / \mathrm{mL}$ & $P$ \\
\hline Age (yr) & $49.0 \pm 20.0$ & $48.9 \pm 17.3$ & 0.983 \\
Vitamin D (ng/dL) & $13.3 \pm 6.3$ & $25.8 \pm 7.0$ & 0.001 \\
$\mathrm{MPV}(\mathrm{fL})$ & $7.9 \pm 1.0$ & $7.5 \pm 1.1$ & 0.003 \\
$\mathrm{Hb}(\mathrm{g} / \mathrm{dL})$ & $12.8 \pm 1.4$ & $13.0 \pm 1.5$ & 0.128 \\
WBC $\left(\times 10^{9} / \mathrm{L}\right)$ & $7.0 \pm 1.9$ & $7.0 \pm 2.4$ & 0.960 \\
Platelets $\left(\times 10^{9} / \mathrm{L}\right)$ & $261 \pm 70$ & $267 \pm 55$ & 0.965 \\
\hline
\end{tabular}

Results are listed as mean \pm SD.

Abbreviations: MPV, mean platelet volume; WBC, white blood cells. levels for both male and female patients in Group 1 was lower than those in Groups 2 and $3(P<0.001$ for all). In addition, vitamin $D$ levels for both male and female patients in Group 2 were lower than those in Group $3(P<0.001)$. For MPV, female patients in Group $1(8.0 \pm 1.0 \mathrm{fL})$ had significantly higher MPV than both male and female patients in Group 3 (men, 7.4 \pm 1.0 fL; women, $7.6 \pm 1.0 \mathrm{fL}, P<0.001$ for all).

MPV and age were dependent variables and the vitamin D level and other hematologic and laboratory parameters were independent variables in the linear regression analysis. Low vita$\min D(\beta=-0.109, P=0.019)$ and FPG $(\beta=0.119, P=0.010)$ were independently associated with a high MPV (Table 4 ). In the Pearson's correlation analysis, a negative correlation was found between the vitamin D level and MPV $\left(r^{2}=0.020, P=0.003\right)$.

\section{DISCUSSION}

In this study, patients were divided into three groups according to the vitamin D level. The MPV in Group 3 was substantially lower than that in Groups 1 and 2. Although the MPV in Group 1 was higher than that in Group 2, the difference was not statistically significant. When comparing patients according to vitamin D levels of $<20 \mathrm{ng} / \mathrm{mL}$ or $>20 \mathrm{ng} / \mathrm{mL}$, the MPV was substantially higher among those with a vitamin D level of $<20 \mathrm{ng} / \mathrm{mL}$. A markedly high MPV in patients with vitamin D level of $<20$

Table 4. Relationship between mean platelet volume and confounding variables by linear regression analysis $\left(r^{2}=0.179, P<\right.$ 0.001)

\begin{tabular}{lcc}
\hline Independent variables & $\beta$ & $P$ \\
\hline Age & 0.012 & 0.797 \\
Vitamin D & -0.109 & 0.019 \\
Glucose & 0.119 & 0.010 \\
Hb & -0.007 & 0.888 \\
Platelets & -0.370 & 0.001 \\
WBC & 0.006 & 0.896 \\
BUN & -0.096 & 0.082 \\
Creatinine & -0.005 & 0.919
\end{tabular}

Abbreviations: WBC, white blood cell; BUN, blood urea nitrogen.

Table 3. Subgroup analysis of vitamin D and mean platelet volume (MPV) for each group stratified by sex

\begin{tabular}{lcccccc}
\hline & Men in group 1 & Women in group 1 & Men in group 2 & Women in group 2 & Men in group 3 & Women in group 3 \\
\hline Vitamin D (ng/mL) & $8.0 \pm 1.7$ & $7.8 \pm 2.6$ & $15.1 \pm 2.9^{*}$ & $15.0 \pm 2.5^{*}$ & $25.1 \pm 4.0^{*, \dagger}$ & $25.9 \pm 7.3^{*, \dagger}$ \\
MPV (fL) & $7.8 \pm 1.2$ & $8.0 \pm 1.0$ & $7.8 \pm 1.0$ & $7.9 \pm 1.0$ & $7.4 \pm 1.0^{\ddagger, \S}$ & $7.6 \pm 1.0^{\ddagger}$ \\
\hline
\end{tabular}

Results are listed as mean \pm SD.

${ }^{*} P<0.001$ vs. both men and women in group $1 ;{ }^{\dagger} P<0.001$ vs. both men and women in group $2 ;{ }^{\ddagger} P<0.001$ vs. women in group $1 ;{ }^{\S} P=0.007$ vs. women in group 2. 
$\mathrm{ng} / \mathrm{mL}$ indicates an increased cardiac risk. When patients were divided into subgroups according to the vitamin D level and gender, the MPVs in both the male and female patients in Groups 1 and 2 were higher than those in both the male and female patients in Group 3, and female patients in Group 1 had higher MPVs than both the male and female patients in Group 3. Vitamin $D$ deficiency was more frequent in women than in men [21]. Male gender is a risk factor for coronary artery disease, while female gender is associated with a lower incidence of coronary artery disease [22]. This study suggests that vitamin $D$ deficiency may be associated with an increased risk of cardiac disease in women with a high MPV, since high MPV is associated with an increased risk of coronary artery disease [5].

Vitamin D insufficiency is very common worldwide and in Turkey [23]. In particular, vitamin D deficiency is common in the Eastern Black Sea region of Turkey $\left(41.2^{\circ} \mathrm{N}\right)[23,24]$. An established relationship between vitamin $\mathrm{D}$ deficiency and cardiac disease exists, and some mechanisms underlying the development of cardiac disease have been proposed [25]. For example, a vitamin D level of $<20 \mathrm{ng} / \mathrm{mL}$ increases the risk of certain cardiac diseases, such as ischemic heart disease, sudden cardiac death, and heart failure [26]. Some studies have reported an increased risk of heart disease, when the vitamin $D$ level is $<10$ $\mathrm{ng} / \mathrm{mL}$ [27]. Another study reported that the prevalence of hypertension increased with a vitamin D level of $<15 \mathrm{ng} / \mathrm{mL}$ [28]. Moreover, calcium plus vitamin D supplementation is thought to reduce systolic and diastolic hypertension [29].

Hypertension and increased cardiac risk due to vitamin D deficiency may be associated with the direct effects of calcium deposition in vascular smooth muscle that may in turn lead to renin-angiotensin system activation, impaired glycemic control, hyperuricemia, and increased levels of inflammatory cytokines $[30,31]$. One experimental study showed that vitamin D receptor (VDR) knockout mice had increased blood pressure, cardiac hypertrophy, and elevated activation of the renin-angiotensin-aldosterone system [32]. These mice demonstrated impaired cardiac relaxation and contractility as well as developed left ventricular hypertrophy [32]. Several small observational and casecontrol studies have suggested that vitamin D deficiency is associated with insulin resistance or impaired insulin secretion, while insulin resistance and hyperglycemia are associated with hypertension and coronary heart disease [33, 34]. A previous study also showed that vitamin $\mathrm{D}$ supplementation given to patients with heart failure decreases symptoms that may be related to decreased levels of inflammatory cytokines [35].

In previous investigations on potential adverse effects of vita- min D deficiency on the heart, MPV (known to cause cardiac events such as myocardial infarction and acute coronary syndrome) has not been considered in the analyses. The balance of body cytokines changes with decreased levels of vitamin D, and the release of cytokines increases TNF- $\alpha$ and IL- 6 levels $[15,16]$. The increased release of cytokines in patients with vitamin D deficiency may be associated with the VDR, a transcription factor that mediates the genomic effects of calcitriol. The VDR is constitutively expressed in monocytes and macrophages. Thus, the release of cytokines such as IL- 6 and TNF- $\alpha$ may be affected. Previous studies have reported decreases in IL- 6 and TNF- $\alpha$ after vitamin D treatment [36]. TNF- $\alpha$ and IL- 6 are related to oxidative stress and stimulate megakaryopoiesis [18]. These cytokines are associated with enhanced oxidative stress that contributes to platelet activation. The induction of this event leads to the release of immature and activated platelets from bone marrow to the circulatory system, thus increasing MPV. Previous studies have shown that vitamin D decreases the expression of vascular cell adhesion molecule (VCAM)-1 and membrane type-1 matrix metalloproteinase (MT1-MMP), therefore preventing platelet activation and decreasing fibrinolysis and thrombosis [19].

We observed that a low vitamin D level was correlated with a high MPV. Vitamin D deficiency increases the release of proinflammatory cytokines such as IL-6 and TNF- $\alpha$ [16] that may lead to a high MPV. Consequently, a high MPV increases cardiac disease risk. One previously reported mechanism suggests that vitamin $\mathrm{D}$ exerts anticoagulant effects by upregulating the expression of an anticoagulant glycoprotein (thrombomodulin) and downregulating the expression of a critical coagulation factor (tissue factor) in monocytes [37]. Therefore, vitamin D derivatives may be developed as new types of antithrombotic agents. A study conducted by Kebapcilar et al. [38] on women diagnosed with primary ovarian insufficiency showed a negative correlation between MPV and the vitamin D level, and Koyama et al. [37] found similar results. The results of our study also coincide with these studies.

This study showed that FPG was strongly associated with an increased MPV. High FPG or hyperinsulinemia may cause an increased MPV. Hyperglycemia can increase platelet reactivity by inducing nonenzymatic glycation of proteins on the surface of the platelets [39]. Additionally, platelet function is directly regulated by insulin via the functional insulin receptor (IR) found on human platelets [39]. Vitamin D plays an important role in insulin secretion, and vitamin D deficiency is associated with glucose intolerance and insulin sensitivity and type 2 diabetes 
[40]. Nonetheless, vitamin D deficiency can lead to the destruction of pancreatic $\beta$-cells via increasing IL-6 and TNF- $\alpha$ levels [17]. Thus, increased levels of cytokines such as IL-6 and TNF- $\alpha$ may lead to hyperglycemia and hyperinsulinemia in patients with vitamin D deficiency. This could explain why the patients in this study had high MPV. Therefore, low vitamin D level may deteriorate the balance between anticoagulant glycoprotein and coagulation factors in favor of coagulation. This event may stimulate the release of platelets and lead to the emergence of large, young platelets into the peripheral circulation.

This study has several limitations. First, the number of enrolled patients was inadequate to reflect the general population. Second, the presence of cardiac disease was not analyzed when comparing MPV with vitamin D deficiency. This should be investigated in future studies. Last, vitamin D supplementation in vitamin D-deficient individuals may decrease MPV; however, it was not analyzed in our study. Further studies are needed to validate our findings.

Vitamin D deficiency is related to an increased incidence of hypertension and cardiac events and increases the release of proinflammatory cytokines such as TNF- $\alpha$ and IL-6. Moreover, vitamin D deficiency may increase hyperglycemia and hyperinsulinemia that may deteriorate the anticoagulant glycoprotein and coagulation factor balance, thereby leading to an increase in MPV. This study suggests that vitamin D deficiency may increase MPV.

\section{Authors' Disclosures of Potential Conflicts of Interest}

No potential conflicts of interest relevant to this article were reported.

\section{REFERENCES}

1. Davì G and Patrono C. Platelet activation and atherothrombosis. N Engl J Med 2007:357: 2482-94.

2. Park Y, Schoene N, Harris W. Mean platelet volume as an indicator of platelet activation: methodological issues. Platelets 2002;13:301-6.

3. Rivera J, Sánchez-Roig MJ, Rosillo MC, Moraleda JM, Vicente V. Stability of glycoproteins Ib/IX and IIb/IIla during preparation and storage of platelet concentrates: detection by binding assays with epitope-defined monoclonal antibodies and physiological ligands. Vox Sang 1994;67: 166-71.

4. Cure MC, Cure E, Kirbas A, Cicek AC, Yuce S. The effects of Gilbert's syndrome on the mean platelet volume and other hematological parameters. Blood Coagul Fibrinolysis 2013;24:484-8.

5. Khode V, Sindhur J, Kanbur D, Ruikar K, Nallulwar S. Mean platelet volume and other platelet volume indices in patients with stable coro- nary artery disease and acute myocardial infarction: a case control study. J Cardiovasc Dis Res 2012;3:272-5.

6. Kodiatte TA, Manikyam UK, Rao SB, Jagadish TM, Reddy M, Lingaiah HK, Lakshmaiah V. Mean platelet volume in Type 2 diabetes mellitus. J Lab Physicians 2012;4:5-9.

7. Cho SY, Jeon YL, Choi SK, Suh JT, Lee HJ, Park TS. Mean platelet volume in Korean patients with acute ischemic stroke: a gender difference. Platelets 2013;24:75-6.

8. Bulur S, Önder HI, Aslantas Y, Ekinozu I, Kiliç AÇ, Yalcin S, et al. Relation between indices of end-organ damage and mean platelet volume inhypertensive patients. Blood Coagul Fibrinolysis 2012;23:367-9.

9. Gulcan M, Varol E, Etli M, Aksoy F, Kayan M. Mean platelet volume is increased in patients with deep vein thrombosis. Clin Appl Thromb Hemost 2012;18:427-30.

10. Kuloğlu O, Gür M, Seker T, Kalkan GY, Sahin DY, Tanboğa IH, et al. Serum 25-hydroxyvitamin D level is associated with arterial Stiffness, left ventricle hypertrophy, and inflammation in newly diagnosed hypertension. J Investig Med 2013;61:989-94.

11. Yousef FM, Jacobs ET, Kang PT, Hakim IA, Going S, Yousef JM, et al. Vitamin D status and breast cancer in Saudi Arabian women: case-control study. Am J Clin Nutr 2013;98:105-10.

12. Wilkins $\mathrm{CH}$, Birge SJ, Sheline YI, Morris JC. Vitamin D deficiency is associated with worse cognitive performance and lower bone density in older African Americans. J Natl Med Assoc 2009;101:349-54.

13. Annweiler C, Schott AM, Rolland Y, Blain H, Herrmann FR, Beauchet O. Dietary intake of vitamin $\mathrm{D}$ and cognition in older women: a large population-based study. Neurology 2010;75:1810-6.

14. Dong Y, Stallmann-Jorgensen IS, Pollock NK, Harris RA, Keeton D, Huang Y, et al. A 16-week randomized clinical trial of 2000 international units daily vitamin D3 supplementation in black youth: 25-hydroxyvitamin D, adiposity, and arterial stiffness. J Clin Endocrinol Metab 2010; 95:4584-91.

15. Beilfuss J, Berg V, Sneve M, Jorde R, Kamycheva E. Effects of a 1-year supplementation with cholecalciferol on interleukin-6, tumor necrosis factor-alpha and insulin resistance in overweight and obese subjects Cytokine 2012;60:870-4.

16. Di Rosa M, Malaguarnera G, De Gregorio C, Palumbo M, Nunnari G, Malaguarnera L. Immuno-modulatory effects of vitamin D3 in human monocyte and macrophages. Cell Immunol 2012;280:36-43.

17. Chakhtoura M and Azar ST. The role of vitamin D deficiency in the incidence, progression, and complications of type 1 diabetes mellitus. Int J Endocrinol 2013;2013:148673.

18. Cure E, Balik MS, Cumhur Cure M, Guvercin Y, Erkut A, Yuce S, et al. Is the mean platelet volume predictive of hip fractures in the elderly? Ann Lab Med 2013;33:367-70.

19. Sorenson M and Grant WB. Does vitamin D deficiency contribute to erectile dysfunction? Dermatoendocrinol 2012;4:128-36.

20. Correia LC, SodreF, Garcia G, Sabino M, Brito M, Kalil F, et al. Relation of severe deficiency of vitamin $D$ to cardiovascular mortality during acute coronary syndromes. Am J Cardiol 2013;111:324-7.

21. Hovsepian S, Amini M, Aminorroaya A, Amini P, Iraj B. Prevalence of Vitamin D Deficiency among Adult Population of Isfahan City, Iran J Health Popul Nutr 2011; 29:149-55.

22. Roeters van Lennep JE, Westerveld HT, Erkelens DW, van der Wall EE. Risk factors for coronary heart disease: implications of gender. Cardiovasc Res 2002;53:538-49.

23. Kirbas A, Kirbas S, Anlar O, Turkyilmaz AK, Cure MC, Efe H. Investigation of the relationship between vitamin $\mathrm{D}$ and bone mineral density in newly diagnosed multiple sclerosis. Acta Neurol Belg 2013;113:43-7.

24. Mithal A, Wahl DA, Bonjour JP, Burckhardt P, Dawson-Hughes B, Eis- 
man JA, et al. IOF Committee of Scientific Advisors (CSA) Nutrition Working Group. Global vitamin D status and determinants of hypovitaminosis D. Osteoporos Int 2009;20:1807-20.

25. Ku YC, Liu ME, Ku CS, Liu TY, Lin SL. Relationship between vitamin D deficiency and cardiovascular disease. World J Cardiol 2013;5:337-46.

26. Cigolini M, lagulli MP, Miconi V, Galiotto M, Lombardi S, Targher G. Serum 25-hydroxyvitamin D3 concentrations and prevalence of cardiovascular disease among type 2 diabetic patients. Diabetes Care 2006;29: 722-4.

27. Zittermann A, Schleithoff SS, Götting C, Dronow O, Fuchs U, Kuhn J, et al. Poor outcome in end-stage heart failure patients with low circulating calcitriol levels. Eur J Heart Fail 2008;10:321-7.

28. Wang TJ, Pencina MJ, Booth SL, Jacques PF, Ingelsson E, Lanier K, et al. Vitamin D deficiency and risk of cardiovascular disease. Circulation 2008;117:503-11.

29. Liu ZM, Woo J, Wu SH, Ho SC. The role of vitamin D in blood pressure, endothelial and renal function in postmenopausal women. Nutrients 2013;5:2590-610.

30. Wang C. Role of vitamin D in cardiometabolic diseases. J Diabetes Res 2013;2013:243934.

31. Judd SE and Tangpricha V. Vitamin D deficiency and risk for cardiovascular disease. Am J Med Sci 2009;338:40-4.

32. Simpson RU, Hershey SH, Nibbelink KA. Characterization of heart size and blood pressure in the vitamin $\mathrm{D}$ receptor knockout mouse. J Ste- roid Biochem Mol Biol 2007;103:521-4.

33. Torun $E$, Gönüllü $E$, Ozgen IT, Cindemir E, Oktem F. vitamin D deficiency and insufficiency in obese children and adolescents and its relationship with insulin resistance. Int J Endocrinol 2013;2013:631845.

34. Sung CC, Liao MT, Lu KC, Wu CC. Role of vitamin D in insulin resistance. J Biomed Biotechnol 2012;2012:634195.

35. Pourdjabbar A, Dwivedi G, Haddad H. The role of vitamin D in chronic heart failure. Curr Opin Cardiol 2013;28:216-22.

36. Schleithoff SS, Zittermann A, Tenderich G, Berthold HK, Stehle P, Koerfer R. Vitamin D supplementation improves cytokine profiles in patients with congestive heart failure: a double-blind, randomized, placebo controlled trial. Am J Clin Nutr 2006;83:754-9.

37. Koyama T and Hirosawa S. Anticoagulant effects of synthetic retinoids and activated vitamin D3. Semin Thromb Hemost 1998;24:217-26.

38. Kebapcilar AG, Kulaksizoglu M, Ipekci SH, Korkmaz H, Kebapcilar L, Akyurek $F$, et al. Relationship between mean platelet volume and lowgrade systemic coagulation with vitamin $D$ deficiency in primary ovarian insufficiency. Arch Gynecol Obstet 2013;288:207-12.

39. Kodiatte TA, Manikyam UK, Rao SB, Jagadish TM, Reddy M, Lingaiah HK, et al. Mean platelet volume in Type 2 diabetes mellitus. J Lab Physicians 2012;4:5-9.

40. Song Y, Wang L, Pittas AG, Del Gobbo LC, Zhang C, Manson JE, et al. Blood 25-hydroxy vitamin $D$ levels and incident type 2 diabetes: a metaanalysis of prospective studies. Diabetes Care 2013;36:1422-8. 